\title{
Competitive Advantage of Firm Strategy
}

\author{
Dhundi Raj Bhattarai (Ph D)
}

Lecturer, Nepal Commerce Campus

\section{Background}

Various authors have defined business strategy in the following dimensions: business strategy is integrated and is a coordinated set of commitments and actions which a company uses to gain a competitive advantage by exploiting core competencies in specific product markets. The main concept of this strategy is to choose to perform activities differently, or to perform different activities, compared to their rivals. In addition, the objective of this strategy is to build unique and strong competencies in one or more areas to gain a competitive advantage over their rivals (Slater \& Olsen, 2000; Thompson \& Strickl, 2003). Dess and Miller (1993) extended the concept of business strategy presented by Porter by combining multiple forms of competitive advantage, specifically integrating differentiation and overall cost strategies to achieve the highest financial and marketing performance for the organization (Wright, Kroll, Tu \& Helms, 1991; Kim and Lim, 1988).

Research suggests that detection of either of the generic strategies, differentiation or cost leadership, enables a firm to achieve better performance (Hambrick, 1983; Miller \& Friesen, 1986). Allen (2007) has found the lack of strategic focus to be a major reason for the downfall of several Japanese firms. Allen (2007) has also found that iconic Japanese firms such as Honda, Sony, and Nintendo "rise to global dominance by their well developed and defined corporate strategies". He goes on to document how other Japanese companies (e.g. Mitsubishi) are using a commitment to Porter's generic strategies as a mechanism for corporate renewal. However, to sustain such superior performance into the future, firms should build effective barriers to prevent imitation of best practices that enable such superior performance. Porter $(1996,2001)$ argues that cost leadership strategy is easily replicable since best practices that enhance cost efficiency can spread rapidly with modern technological innovations. Conversely, a differentiation strategy is harder to imitate since it is built on products or services that are perceived to be different from the competitors; hence leading to more sustainable performance. To the extent that the superior performance through strategic positioning of firms can be sustained into the future contemporaneous measures such as earnings or ROA do not capture this persistence. Even so, the stock markets should theoretically recognize and reward the profitability implications of the superior performance resulting from the strategy pursued by firms. 


\section{Review of the relevant literature}

The empirical evidence on linking strategic practices and organizational performance has been organized into five parts.

I. Review of major studies during 1980s

II. Review of major studies during 1990s

III. Review of major studies during 2000s

IV. Review of major studies during 2010s

V. Review of major studies in Nepalese context.

\section{Review of major studies during 1980s}

The brief summary with their findings are as follows.

Table 1

Major studies during 1980s

\begin{tabular}{ll}
\hline Study & Major findings \\
\hline $\begin{array}{l}\text { Zeithaml and Fry } \\
\text { (1984) }\end{array}$ & $\begin{array}{l}\text { Superstars are more efficient in their product use of R \& D, or perhaps } \\
\text { that they benifitted from R \&D of earlier market entrants. }\end{array}$ \\
Govindarajan (1988) & $\begin{array}{l}\text { High managerial internal locus of control and low emphasis on meeting } \\
\text { a budget are associated with high performance in SBUs employing a } \\
\text { strategy of differentiation. }\end{array}$ \\
\hline Segev (1989) & $\begin{array}{l}\text { Similarities and differences between the two typologies which are Porter } \\
\text { (1980) and Miles and Snow (1978) }\end{array}$ \\
\hline
\end{tabular}

A study on contextual and strategic differences among mature businesses in four dynamic performance situations which were business referred to "superstars" have registered substantial increase in both market share and profitability, "harvesters", on the other hand, have increased profits and loss market share. "Builders," have increased market share, but face eroding profitability. "Decliners," suffer losses in both market share and profitability. Its has been found that in perspective of research and development expenditure (R\&D) variable new products represented a significantly higher percentage of sales for superstars than for harvesters, builders, and decliners. Superstars also introduced a significantly higher percentage of new products relative to competitors than did harvesters and decliners. These results suggest that superstars were more efficient in their use of product $R \& D$, or perhaps that they benefitted from the R\&D of earlier market entrants (Zeithaml \& Fry, 1984).

Similarly, a study on contingency approach to strategy implementation at the business-unit level in the perspective of integrating administrative mechanisms with strategy has been examined by Govindarajan (1988). This study has focused on what is perhaps the most critical aspect of strategy implementation in large, multi-business organizations: recognizing that different business units within the same corporation often pursue different strategies and at the administrative mechanisms that corporate headquarters use to manage those businesses should differ. Data for the study have been collected from strategic business unit (SBU) general managers and their superiors at 24 firms on the Fortune 500 list (sales range: $\$ 450$ million to $\$ 37$ billion). The firms represent both growing and mature industries, including the automotive, petroleum, 
food products, chemical production, aerospace, electronics, consumer durables, clothing manufacture and retail, and various consumer nondurable industries. The study explains that for SBUs employing a strategy of differentiation, deemphasizing budgetary goals during performance evaluations is likely to be associated with high SBU effectiveness. It also clarifies that SBUs employing a strategy of differentiation, greater internal locus of control on the part of an SBU general manager is likely to be associated with high SBU effectiveness. For SBUs employing a strategy of low cost, greater external locus of control on the part of an SBU general manager is likely to be associated with high SBU effectiveness.

A systematic comparative analysis and synthesis of two business level strategies has been examined by Segev (1989). The study places spotlight on two important business-level strategic typologies which have been systematically evaluated, analyzed and compared to Porter's overall cost leadership, differentiation, focus, and stuck in the middle i.e. generic competitive strategies, and Miles and Snow's defender, prospector, analyzer, and reactor types of organizational adaptation. On the basis of strategic theory, and following a pilot study, 31 strategic variables have been evaluated by judges on a seven-point maximum-minimum scale, for each strategy, within its typology. Analysis of the matrix of relative proximities among the strategic profiles of the two business-level strategic typologies indicates that Miles and Snow's defender is closest to Porter's cost-focus; prospector is closest to differentiation; analyzer to differentiation and cost-focus and the reactor is stuck in the middle. Inspection of the horizontal rows reveals that Porter's cost-leader is closest to Miles and Snow's analyzer and defender; cost-focus to analyzer; differentiation-focus to both prospector and analyzer; and the stuck in the middle is clearly a reactor.

\section{Review of major studies during 1990s}

Research work undertaken in between 1981-1990, is mentioned in the table 3.2.

Table 2

Major studies during 1990s

\begin{tabular}{ll}
\hline Study & Major findings \\
\hline $\begin{array}{l}\text { O'Farrell, Hitchnes and } \\
\text { Moffat (1992) }\end{array}$ & $\begin{array}{l}\text { Firms pursuing differentiation strategies export significantly more } \\
\text { than companies of similar size, age and service type implementing a } \\
\text { stuck-in-the middle policy }\end{array}$ \\
\hline Davis and Schull (1993) & $\begin{array}{l}\text { Sharing of resources and programs among business units positively } \\
\text { influences performance in low-cost firms and sharing did not affect } \\
\text { the performance of firms in differentiation-based strategic clusters }\end{array}$ \\
\hline $\begin{array}{l}\text { Marlin, Lamont, and } \\
\text { Hoffman, (1994) }\end{array}$ & $\begin{array}{l}\text { In differentiated and maximum choice situations, most of the } \\
\text { hospitals pursued a differentiation strategy. }\end{array}$ \\
\hline Kling and Smith (1995) & $\begin{array}{l}\text { Five airlines appear to be successfully following one of the three } \\
\text { generic strategies and therefore enjoy better competitive positions in } \\
\text { the industry and superior profitability }\end{array}$ \\
\hline Lassar and Kerr (1996) & $\begin{array}{l}\text { Distribution intensity for cost leaders and differentiators is high and } \\
\text { significantly different. }\end{array}$ \\
\hline Kaymak (1998) & $\begin{array}{l}\text { Domestic firms possess more of the low cost and/or focus strategies } \\
\text { than MNEs (multinational enterprises) are not pursuing a } \\
\text { differentiation strategy relative to domestic firms. }\end{array}$ \\
\hline
\end{tabular}


O'Farrell, Hitchnes, and Moffat (1992) have analyzed generic strategies and performance in business service firms. This study has been undertaken on data from a sample of firms in Scotland and the South- East of England drawn from the market research, graphic design, product design, advertising and marketing, and management consultancy industries. The focus of the analysis is to determine whether firms pursuing a clear-cut strategy (focus differentiation, differentiation or low cost leadership) achieved a superior performance to firms which do not (i.e. were stuckin-the-middle, in terms of Porter's model). According to the conclusion, 5 firms being categorised as adopting a cost focus strategy and only 3 competing on the basis of cost leadership. 28 businesses have been implemented to have a focus differentiation strategy, 27 were competing on the basis of differentiation and 20 were 'stuck in the middle', not competing on the basis of low cost or specializing in terms of either services offered or market segments targeted. Hence, only a minority of companies in the sample have been found to have tried to compete on costs; most were attempting to differentiate or were stuck in the middle. Similarly, firms pursuing differentiation strategies have been found to export significantly more than companies of similar size, age and service type implementing a stuck-in-the-middle policy. The two groups of firms generate similar proportions of repeat business; while the differentiators achieved an average net profit on turnover of 11.1 percent compared with 10.3 percent.

Davis and Schull (1993) have examined on addressing the contingent effects of business unit strategic orientation on relationship between organizational context and business unit performance. This study critically looks at the moderate role of strategic orientation on relationships between organizational context variables and measures of business unit performance. Study, which has used cluster analysis and the regression analysis tools to analyse the data collected from paper and pulp manufacturing industry through internet at the headquarters and plant sites of twelve companies, and also from questionnaires mailed to chief executive officers (or their designated representatives) of 1382 business units of American pulp and paper industry, reveals that the sharing of resources and progrmmes among business units positively influences performance in low-cost firms and that sharing does not affect the performance of firms in differentiation-based strategic clusters. According to its findings, Sharing of resources and programs among business units positively influences performance in low-cost firms and sharing did not affect the performance of firms in differentiationbased strategic clusters.

Marlin, Lamont, and Hoffman (1994) critically look at examined on choice situation, strategy and performance reexamination. This study examines strategy and performance relationships between and within situations of varying strategic choice and environmental determinism. The examination focussed on 147 Florida hospitals in 1988 classifies each hospital strategy as differentiation, cost leadership or muddling. The classifications are based on three measures of differentiation and three indicators of cost orientation. The differentiation indices have been technological sophistication of service offerings, breadth of service offerings, and number of rare service offerings. Low cost orientation has been found to be based on three measures: total expenses divided by the average number of occupied beds for each hospital, cost adjusted per patient 
day and salary adjusted per patient day. The findings reveal that in differentiated and maximum choice situations, most of the hospitals in this sample pursue a differentiation strategy. Except for the incremental choice situation, differentiators within each choice situation are higher performers than cost leaders, which are higher performers than muddlers.

Kling and Smith (1995) have identified strategic group in the U.S. airline industry from the perspective of application of Porter's model. This study identifies strategic groups among the nine major U.S. passenger airlines by utilizing the framework of Michale Porter's generic strategy typology. Standardized cost data and the use of the National Institute for Aviation Research have allowed strategic groups to be accurately determined through the use of a cost/quality differentiation scatterplot diagram. Profitability analysis largely validates the use of the Porter model to identify strategic groups in the U.S. airline industry. According to the findings, five airlines appear to be successfully following one of the three generic strategies and therefore, enjoy better competitive positions in the industry and superior profitability, and a group of three airlines is clearly identified as lacking in strategic focus and suffers from poor financial performance.

A study on influence of competitive strategy on the relationship between suppliers and their distribution network, data have been collected within the stereo speaker segment of the consumer electronic industry in the USA. Cluster analysis has been used to show distinct differences in channel management and structure for the three generic strategies of cost leadership, differentiation and focus. Its findings recommended that cost leadership utilizes high intensive distribution, differentiator utilizes moderately and focus manufactures utilize low distribution intensity. Distribution intensity refers to the number of distributors used by a manufacturer with in a given trade area (Lassar \& Kerr 1996).

Additionally, a study on Kaymak (1998) critically investigates on domestic firms which exhibit higher levels of the focus strategy than multinational enterprises (MNEs). It explains that domestic firms have significantly greater low cost strategy than MNEs do. Domestic firms focused on low cost strategies do exhibit higher levels of performance but a statistically significant difference is not detected. MNEs showing score high on low cost also exhibit more of the differentiation strategy. MNEs do not follow low cost strategy and exhibit similar differentiation strategies relative to domestic firms.

\section{Review of major studies during 2000s}

The major literature on impact of strategic choice out of differentiation and cost leadership and its impact on organizational performance have been shown in table 3.3.The key studies in this period were firm strategy, differentiation strategy, cost leadership strategy, capital market perception, capital markets and management strategy including Miles and Snow typology. The stuis in different competitive environments in different size in different enterprizes in manufacturing and sevice sector of different nations. 
Table 3

Major studies during 2000s.

\begin{tabular}{ll}
\hline Study & Major findings \\
\hline Kathuria and Porth (2003) & $\begin{array}{l}\text { Manufacturing units pursuing dissimilar strategies are led by } \\
\text { manufacturing managers with dissimilar attributes. }\end{array}$ \\
\hline Koo, Koh, and Nam (2004) & Porter's competitive strategies are relevant to electronic markets. \\
\hline $\begin{array}{l}\text { Auzair and Langfield-Smith } \\
\text { (2005) }\end{array}$ & $\begin{array}{l}\text { Firms pursuing a cost leadership strategy place greater emphasis } \\
\text { on a more bureaucratic management control systems (MCS) than } \\
\text { firms pursuing a differentiation strategy }\end{array}$ \\
\hline $\begin{array}{l}\text { Wang, Zantow, Lai, and } \\
\text { Wang (2006) }\end{array}$ & $\begin{array}{l}\text { differentiation strategy to cope with the intense competition } \\
\text { faced in mainland china's immense logistics market. }\end{array}$ \\
\hline $\begin{array}{l}\text { Huo, Selen, Yeung, and } \\
\text { Zhao (2008) }\end{array}$ & $\begin{array}{l}\text { Low cost operations emphasis will lead to worsen financial } \\
\text { performance. }\end{array}$ \\
$\begin{array}{l}\text { Gomes, yasin, and lisoba } \\
\text { (2009) }\end{array}$ & $\begin{array}{l}\text { Portuguese small and medium enterprises manufacturing } \\
\text { organizations are following strategic orientations. }\end{array}$ \\
$\begin{array}{l}\text { Leitner and Guldenberg } \\
\text { (2010) }\end{array}$ & $\begin{array}{l}\text { Firms that follow a combination strategy outperform companies } \\
\text { with neneric strategy in terms of profitability and growth } \\
\text { and achieve higher profitability than companies that follow a } \\
\text { differentiation strategy. }\end{array}$ \\
\hline
\end{tabular}

A study on strategy-managerial characteristics alignment and performance in a manufacturing perspective based on a sample of 196 managers from 98 companies has been conducted by Kathuria and Porth (2003). Its findings reveal that companies should select and place manufacturing managers with different characteristics depending upon their strategic orientation. Manufacturing managers with higher education and shorter job and organizational tenures seem to perform better. On the other hand, the managerial profile that seems to fit a low cost orientation includes managers with higher job and organizational tenures and lower levels of education. Another implication for senior managers is the need to consider reassigning functional managers when changing the strategic orientation of manufacturing units within a corporation.

Similarly, a study on examination of Porter's competitive strategies in electronic virtual markets in a comparison of two on-line business models examines the connection between four competitive strategies (cost leadership, market differentiation, innovation differentiation, market focus) in business performance of electronic markets. A survey of 123 firms in South Korea has found that click and mortar firms tend to favor strategies based on differentiation more than wholly on-line firms, but that the two groups do not differ significantly with regard to strategies based on cost leadership and market focus. Result of the regression analysis has been mixed. For on-line firms, both differentiation strategies, market differentiation and innovation differentiation, have been found to be good performance predictors, but cost leadership and market focus have not been. On the other hand, the market focus strategy turns out to be the only effective performance predictor for click-and-mortar firms (Koo, Koh, \& Nam, 2004).

Auzair and Langfield-Smith (2005) have studied on the effect of service process type, business strategy and life cycle stage on bureaucratic management control 
systems (MCS) in service organizations. This study adopts a contingency approach and uses empirical analysis to identify the influence of specific organizational variables on the design of MCS in service organizations across several industries. This study falls back on the survey method to investigate the influence of several contingent variables on the design of MCS in service organizations. MCS is conceptualized in terms of five dimensions: action/results controls, formal/informal controls, tight/loose controls, restricted/flexible controls, and impersonal/interpersonal controls to form a composite measure of the degree of MCS bureaucracy. The framework used in this study recognizes that the service process type, business strategy, and stage in the organizational life cycle influence the choice of MCS design within an organization. The t test and multiple regression analysis of the data collected through the administrating of questionnaires to financial controllers operating in Ausralia concludes that more bureaucratic form of MCS are found in cost leaders in comparision to differentiation. As business strategy has been measured as two separate scales of cost leadership and differentiation, the sample consists of firms that are (1) high on both strategies, (2) low on both strategies, and (3) low on one strategy, but high on the other. A median split has been undertaken to separate high cost leaders from low cost leaders, and high differentiators from low differentiators. Cost leaders have been defined as those firms placing high emphasis on a cost leadership strategy but low emphasis on differentiation. Differentiators have been those firms that place a high emphasis on a differentiation strategy and a low emphasis on cost leadership.

Likewise, a study on strategic postures of third-party logistics providers in mainland China has focused on four logistic pure cost, pure differentiation, cost as well as differentiation, and no advantage. The study asks survey respondents to indicate their business performance compared with their competitors. The business performance of different strategic types is measured on the basis of overall financial performance: average growth in annual sales, average growth rate in market share, percentage growth in return on assets, percentage growth in profit on sales over the past two years. It is suggested that the highest level of business performance was indicated for the companies that successfully pursue both differentiation and cost. The pure differentiation performs higher than pure cost companies. The companies that are not seen as pursuing either of the strategies are the poorest performers. There is no significant difference between performance of pure a cost companies and neither follows cost nor follows differentiation (Wang, Zantow, Lai, \& Wang, 2006).

Similarly, a study on understanding drivers of performance in the third party logistics (3PL) industry in Hong Kong has been conducted by Huo, Selen, Yeung, and Zhao (2008). The sampling tool for this study comprised all members of the Hong Kong Logistics Association (HKLA), with Hong Kong as the population of interest. This study reveals that a low cost emphasis significantly influences on cost performance whereas differentiation significantly influenced on service performance. Differentiation enhances financial performance through the imporovement of service performance. However, differentiation has no significant direct influence on financial performance. Low cost emphasis has a negative influence on financial performance. The negative effect on financial performance of pursuing a pure low cost emphasis prompts many 
3PL providers to seek for differentiation order winners. The results also indicate that functional involvement significantly influences a differentiation emphasis and service performance, but has no significant influence on low cost emphasis or cost performance.

Benchmarking competitive methods and strategic choices of Portuguese small and medium enterprises (SMEs) have been examined by Gomes, Yasin, ans Lisoba (2009). The study focuses on 'analyze and bench mark the strategic approaches.' After the study of cross-sectional sample of 68 Portuguese manufacturing organizations, it explains that the hybrid generic strategies tend to emphasize competitive methods almost equally but it is difficult to establish clear strategic orientations. Perhaps, this hybrid strategic orientation is dictated by the markets in which they are competing. In this context, benchmarking the strategic choices of successful European firms may help Portuguese firms validate and modify their strategic choices.

Generic strategies and firm performance in small and medium enterprises (SMEs) from the perspective of a longitudinal study of Austrian SMEs has been conducted by Leitner and Guldenberg (2010). The data used to test the study's hypotheses have been taken from a longitudinal study of Austrian SMEs with 20-500 employees. This study measures strategic behavior by three dimensions which were cost-efficiency, differentiation by quality and differentiation by innovation to classified generic strategies. Based on these three different strategies, the study constructs the combination strategy by categorizing those companies that have combined costefficiency and differentiation by quality or product innovation (equivalent to calculating an interaction term). Firms that have changed strategy (e.g., followed a cost-efficiency strategy in 1995 and a combination strategy in 2003, or have only followed a generic strategy in one period) have been categorized as 'strategy changed'. Companies which have been unable to identify a generic strategy in either period have been classified as having "no generic strategy". Three performance indicators have been used in the study for both time periods, namely average profitability, turnover growth and employment growth.

An initial analysis of the strategies followed by the participating firms reveals the significance of the different generic strategies. Overall, the most common strategy has been the pure differentiation strategy, pursued over the entire period by 34 firms. In total, 23 of the firms follow a combination strategy, combining cost-efficiency with quality differentiation and product innovation respectively. Only a minority of firms (13) follows a pure cost-efficiency strategy in both periods. The findings reveal that a combination strategy positively influences all three performance indicators profitability, employment growth and turnover growth. SMEs pursuing a combination strategy will achieve greater financial performance and growth than those with no strategy. SMEs that persistently follow a cost-efficiency or differentiation strategy equally performed well, SMEs that pursue a combination strategy achieved equal or greater financial performance than SMEs with cost-efficiency or differentiation strategies.

\section{Review of major studies during 2010s}

The summary of their research pointed out the following findings. 
Major studies during 2010s

\begin{tabular}{ll}
\hline Study & Major findings \\
\hline $\begin{array}{l}\text { Castellanos and Martin } \\
\text { (2011) }\end{array}$ & $\begin{array}{l}\text { The companies that effect a differentiation strategy invest more } \\
\text { money in training (an average of 3.5 percent of their total sales) } \\
\text { than those which adopt a cost leader strategy (1.3 percent) }\end{array}$ \\
\hline Parnell, Lester, Long, and & $\begin{array}{l}\text { The combination strategy-performance linkage has been supported } \\
\text { in Turkey and the USA. In China, the highest performing } \\
\text { strategic group has emphasized a focus orientation accompanied } \\
\text { by neither cost leadership nor differentiation, and has the lowest } \\
\text { performing group was comprised of low cost businesses. }\end{array}$ \\
Koseoglu (2012) & $\begin{array}{l}\text { Capital markets place a higher value on firms pursuing a } \\
\text { differentiation strategy compared to a cost leadership strategy }\end{array}$ \\
\hline $\begin{array}{l}\text { Asdemir, Fernando, and } \\
\text { Tripathy (2013) }\end{array}$
\end{tabular}

Castellanos and Martin (2011) have studied on training as a source of competitive advantage: performance impact and the role of firm strategy, the Spanish case. Their study analyzes the existing relationship between training and business strategies. The object population of this study is made up of Spanish companies with more than 50 employees, since medium-sized companies do not tend to have a formalized unit with which to manage HR. Of the total number of companies, limited ones have only excluded public administration, defense, education and health. These companies think that the training processes in these activities are subject to different criteria to those of the remaining sectors. The information has been gathered through a postal questionnaires addressed to the person in charge of the company's HR department, or failing this, to the managing director. The collection of the questionnaires, which has elicited a total of 118 valid responses, represents a response rate of 20.6 percent. According to its findings, it is indicated that differences exist between them, which is to say that according to the companies in the sample, the companies that effect a differentiation strategy invest more money in training (an average of 3.5percent of their total sales) than those which adopt a cost leader strategy (1.3 percent).

Additionally, a study on how environmental uncertainty affects the link between business strategy and performance in small and medium enterprises (SMEs) as evidenced from China, Turkey, and the USA has been conducted by Parnell, Lester, Long, and Koseoglu (2012). To accommodate the manufacturing firms included in each country's sample, organizations with 250 or fewer employees have been classified as SMEs in usable samples of 94, 383, and 192 for China, Turkey, and the US respectively. Businesses in each nation have been suggested to cluster analyses (Ward's method) along the individual cost, focus, and differentiation items to generate strategic groups. The findings disclose that factor results and alpha scores from each of the three nations suggest that the basic concepts of cost leadership, differentiation, and focus are universal. Cluster results indicate that how these strategic dimensions are conceptualized into a coherent approach differs markedly across nations. The combination strategy-performance linkage has been supported in Turkey and the USA. In China, the highest performing strategic group has emphasized a focus orientation accompanied by neither cost leadership nor differentiation, and the lowest performing 
group is comprised of low cost businesses.

Asdemir, Fernando, and Tripathy (2013) have studied on capital market perception of firm strategy. The aim of this study is to empirically investigate how capital markets perceive and reward the strategies pursued by firms. Compustat data files and stock market returns from CRSP for the period 1989-2009 have been covered to measure strategy and performance variables. In this study, 28,582 firm year and 4,351 unique firms have been included after factor analysis, three variables: selling, general and administrative expenses divided by sales, research and development expenditure divided by sales and sales divided by cost of goods sold were supported to differentiation strategy and other three variables: sales divided by capital expenditure, sales divided by book value of plant and equipment and total number of employees divided by total assets have been supported cost leadership strategy.

Capital market perception has been measured in two ways: Tobins Q and abnormal market returns. This study recommends that market showed place a positive value on firms successfully pursuing either a cost leadership or a differentiation strategy; moreover markets showed place a higher value on firms pursuing a differentiation strategy compared to a cost leadership strategy.

\section{Review of major studies in Nepalese context}

The studies undertaken in Nepalese context highlights the following findings Table 5

\section{Major Studies undertaken in Nepalese context}

\begin{tabular}{ll}
\hline Study & Major findings \\
\hline Shrestha (2001) & $\begin{array}{l}\text { Product pricing has not been appropriate; customers have low purchasing } \\
\text { power and want for cheaper products, hence, strategies must address this } \\
\text { situation. }\end{array}$ \\
\hline \multirow{2}{*}{ Khanal (2003) } & $\begin{array}{l}\text { Strategic influence the performance variables like access to market, } \\
\text { building image and market share, generating sales growth and better } \\
\text { utilization of resources and improving productivity. }\end{array}$ \\
\hline \multirow{2}{*}{ Manandhar (2005) } & $\begin{array}{l}\text { Strategic management affected positively to performance variables and } \\
\text { lack of strategic actions will lead to inertia ultimately which may prove to } \\
\text { be a cause of closure of the enterprise }\end{array}$ \\
\hline Thapa (2013) & $\begin{array}{l}\text { Performance differences between commercial banks employing different } \\
\text { generic strategies and differences are statistically significant. }\end{array}$ \\
\hline
\end{tabular}

Marketing strategies in textile industry of Nepal has been analyzed by Shrestha (2001). The objective of this study is to evaluate the marketing practices and strategies being followed by Nepalese textile industries. This study is based on survey and analytical designs to attain defined objectives. The study is confined to textile industries of spinning and weaving category. There are 134 textile industries of spinning and weaving category. Out of 134 textile industries, 44 have been selected. Both primary and secondary data have been used for this study. Primary data have been collected through questionnaires. Secondary data have been collected from official records, publications, annual reports, economic surveys, journals and magazines and both published and unpublished books/reports. The findings explain that the enterprises 
have been found to be engaged in the evaluation of the strategies and policies, which are in general rated not very satisfactory. This shows that these are weakness in strategy formulation. Therefore, the total strategy formulation exercises are lacking. It appears to be inefficient and not transparent. Market competition is strong but strategy does not appear to be capable enough to meet the situation. It reveals that the pricing strategy may not be appropriate as per the market situation.

The enterprises have concentrated or given emphasis on cost only. The enterprises have been found to be higher price new products. Moderate price is charged for established products and low pricing for declining products. Customers are reported to be financially handicapped. It shows that product pricing has not been appropriate. Customers have low purchasing power and want for cheaper products. Hence, strategies must address this situation.

A study on pricing strategy in Nepalese manufacturing corporations has been examined by Khanal (2003). The study focuses on the impact of pricing upon overall operations, present pricing policies and strategies of Nepalese manufacturing corporations. It also places the spotlight on the manufacturing public corporations (MPC) of Nepal. During the study period, there were 13 MPCs out of 43 public corporations in Nepal. Out of $13 \mathrm{MPCs}, 7$ have been selected as samples. Primary and secondary data have been used for this study. Primary data have been collected from Government, employees, shareholders, creditors, debtor's consumers, general public and agencies by way of questionnaires, interviews, visits and opinion survey. The source of secondary data in this study have been publications and reports of corporations of public, private and other publications such as reports, books and libraries, newspapers, journal research papers, magazines, bulletins, pamphlets statements were the sources of this study. Central bureaus of statistics, ministry of finance, various ministries, trade promotion center Nepal planning commission are other institutions from where necessary secondary data have been collected. Statistical methods and techniques such as mean, median, mode and other mathematical and statistical tools formulae and equations have been applied for the purpose of interpretation and drawing conclusion. Co-efficient of correlations, regression analysis and standard deviation have used in this study. The findings disclose that most of the MPCs have been found adopting "cost oriented pricing method" in practice. Besides, they also follow discriminating pricing method based on regions, consumers, capacity and quality of the product. This study recommends that strategies should be developed tactfully effectively and competitively to win the strategic battle of pricing.

A study on strategic management in Nepalese enterprises has been examined by Manadhar (2005). The basic objective of this study is to identify the process of strategic management and to evaluate the impact of strategic management on performance. Manandhar makes a comparative study between public and private sectors from the perspective of strategic management and performance. A descriptive cross-sectional analysis research design has been followed for this study. 15 enterprises both from the public and private sector have been selected judgmentally including, both manufacturing and service sectors. Eight enterprises have been selected from the private sector and seven from the public sector. Both primary and secondary data have been used for

$$
\sim 40 \sim
$$


this study. Performance indicators have been calculated for the period of 1995-96 to 1999-2000. Primary data have been collected from 251 questionnaires based on fiveposit Likert Scale. Hypothesis has been tested using t-test, p-value, rank correlation, z-test and regression analysis. The findings of this study clearly show that proper strategic management including design, implementation and improvement leads to success. Improvement in the strategic management process requires the cration of a conductive operational environment in an organization. Strategic management tends to be more effective only when the structure is appropriate, organizational climate is warm and management process like decision making, communications, co-ordinations and monitoring and controlling the properly established. Strategy influences the performance variables like access to market, building image and market share, generating sales growth and better utilization of resources and improving productivity. The results of the test of hypothesis confirm the existence of difference in the public and private sector enterprises in respect to organization structure, management practice and aspects of that strategic management. Similarly, the result further shows that strategic management positively affects performance variables. Lack of strategic actions leads to inertia, which may prove to be a cause of closure of the enterprise in the long run.

Thapa (2013) has examined the applicability of generic strategy and firm performance in banking industry in Nepal. The focus is on performance difference between the generic strategy types. Primary and secondary data have been used for this study. Primary data have been collected through structured questionnaire. Secondary data have been collected through annual report. Out of total population 32 commercial banks, 20 commercial banks have been taken as samples. Likert-scale test has been used to check reliability and validity of the questionnaire. Value of Cronbatch Alpha is 0.77 . The findings suggest that commercial banks employing the combination of differentiation and focus on a specific market and commercial banks employing a pure differentiation strategy had higher performance than other commercial banks employing other generic strategies within each generic strategy, only emphasize on the cost cutting and internal efficiency programme which contribute to the prediction of performance but which is not statistically significant.

To sum up, the above major studies on critical strategic practices are significantly associated with organizational performance for each of Porter's generic strategies. Previous studies have not identified strategic practices associated with Porter's generic strategies in Nepalese organizations. Because a chosen strategy is a set of operationalized practices and tactics, understanding the critical practices linked with organizational performance for each generic strategy can provide a clearer guidance for top management and strategic planners. These priorities require a focused action toward organizational success, as evidenced from the organization's performance in Nepalese organizations. Study on impact of factor loaded strategic practices, i.e. product differentiation, cost leadership on capital market perception of Nepalese enterprises, is still remaining.

\section{Conclusion}


Organization either manufacturing or service are successful to take competitive advantage from cost leadership and differentiation strategy. But in the perspective of costleadership and differentiation strategy, their financial performance is mixed in organization. In global perspective differentiation strategy is better than cost leadership strategy but in our nation cost leadership strategy is better than differentiation strategy but differentiation strategy cannot be ignored according to above major studies.

\section{References}

Allen, R.S. (2007). Porter's generic strategies: An exploratory study of their use in Japan. Journal of Business Strategies, 24(1), 69-90.

Asdemir, O., Fernando, G.D., \& Tripathy (2013). Market perception of firm strategy. Managerial Finance, 39(2), 90-115.

Auzair, S. M., \& Langfield-Smith, K. (2005). The effect of service process type, business strategy and life cycle stage on bureaucratic MCS in service organizations. Management Accounting Research, 16, 399-421.

Castellanos, R. M. M., \& Martin, M. Y. S. (2011). Training as a source of competitive advantage: Performance impact and the role of firm strategy, the Spanish case. The International Journal of Human Resource Management, 22(3), 574-594.

Davis, P.S., \& Schul, P.L. (1993). Addressing the contingent effects of business unit strategic orientation on relationships between organizational context and business unit performance. Journal of Business Research, 27(3), 183-200.

Dess, G.G., \& Miller, A. (1993). Strategic Management. McGraw-Hill, New York, NY.

Gomes, C. F., Yasin, M. M., \& Lisoba, J.V. (2009). Benchmarking competitive methods and strategic choices of Portuguese SMEs: Traditional practices and new realities. Benchmarking: An International Journal, 16(6), 729-740.

Govindarajan, V. (1988). A contingency approach to strategy implementation at the business unit level: Integrating administrative mechanisms with strategy. Academy of management Journal, 31(4), 828-853.

//Hambrick, D.C. (1983). Some tests of the effectiveness and functional attributes of miles and snow's strategic types. Academy of Management Journal, 26(1), 5-26.

Huo, B., Selen, W., Yeung, J. H., \& Zhao, X. (2008). Understanding drivers of performance in the 3PL industry in Hong Kong. International Journal of Operation \& production Management, 28(8), 772-800.

Kathuria, R., \& Porth, S. J. (2003). Strategy-managerial characteristics alignment and performance: A manufacturing perspective. International Journal of operation \& production management, 23(3), 255-276.

Kayamak, T. (1998). Business level strategy and performance in a global industry (Unpublished doctoral dissertation). Dean of the Graduate School, Texas Technical University, Texas, U.S.A.

Khanal, V. (2003). A study of pricing strategies in Nepalese manufacturing companies (Unpublished doctoral dissertation). Faculty of Management Kumau University, Nainital, Uttaranchal, India.

Kim, L., \& Lim, Y. (1988). Environment, generic strategies, and performance in a rapidly developing country: A taxonomic approach. Academy of Management Journal, 31(4), 802-827.

Kling, J.A., \& Smith, K.A. (1995). Identifying strategic groups in the US airline industry: An application of the Porter model. Transportation Journal, 35(2), 26-34. 
Koo, C, M., Koh, C. E., \& Nam, K. (2004). An examination of Porter's competitive strategies in electronic virtual markets: A comparison of two on-line business models. International Journal of Electronic Commerce, 9(1) 163-180.

Lassar, W. M., \& Kerr, J. L. (1996). Strategy and control in supplies-distributor relationships: An agency perspective. Strategic Management Journal, 17, 613-632.

Leitner, K., \& Guldenberg, S. (2010). Generic strategies and firm performance in SMEs: A longituditional study of Austrian SMEs. Small Bus Econ, 35, 169-189.

Manandhar (Bajracharya), S. (2005). Strategic management in Nepalese enterprises (Unpublished doctoral dissertation). Faculty of Management, Tribhuvan University, Kathmandu, Nepal.

Marlin, D., Lamont, B. T., \& Hoffman, J. J. (1994). Choice situation, strategy and performance: A reexamination. Strategic Management Journal, 15, 229-239.

Miller, D., \& Friesen, P.H. (1986). Porter's (1980) generic strategies and performance: An empirical examination with American data. Part I: testing porter. Journal of Management Studies, 7, 37-55.

O'Farrell, P.,Hitchnes, D., \& Moffat, L. (1992). Does strategy matter? An analysis of generic strategies and performance in business service firms. Business Strategy Review, 3(1), 71-87.

Parnell, J. A., Lester, D. L., Long, Z., \& Koseoglu, M. A. (2012). How environmental uncerntainty affects the link between business strategy and performance in SMEs: Evidence from China, Turkey, and the USA. Management Decision, 50(4), 546-568.

Porter, M. E. (2001). Strategy and the internet. Harvard Business Review. Mar, 62-78.

Porter, M.E (1996). What is strategy? Harvard Business Review. Nov-Dec, 59-79.

Segev, E. (1989). A Systematic comparative analysis and synthesis of two business-level strategic typologies. Strategic Management Journal, 10(5), 487-505.

Shrestha R. K. (2001). Marketing strategies in textile industry (Unpublished doctoral. dissertation). Faculty of Management, Tribhuvan University, Kathmandu, Nepal.

Slater, S.F., \& Olson, E.M. (2000). Strategy type and performance: The influence of sales force management. Strategic Management Journal, 21, 813-829.

Thapa, B. R. (2013). Testing the applicability of generic strategy and firm performance in banking industry in Nepal (Unpublished M. Phil. dissertation). Faculty of Management, Tribhuvan University, Kathmandu, Nepal.

Thompson, A.A. Jr \& Strickland, A.J. (2003). Strategic management: Concepts and case. 11th ed., McGraw-Hill, New York, NY.

Wang, Q., Zantow, K., Lai, F., \& Wang, X. (2006). Strategic postures of third-party logistics providers in mainland China. International Journal of Physical Distribution \& Logistics Management, 36(10), 793-819.

Wright, P., Kroll, M., Tu, H., \& Helms, M. (1991). Generic strategies and business performance: An empirical study of the screw machine products industry. British Journal of Management, 2(1), 57-65.

Zeithaml, C. P., \& Fry, L. W. (1984). Contextual and strategic difference among mature business in four dynamic performances. The Academy of Management Journal, 27(4) 841-860. 